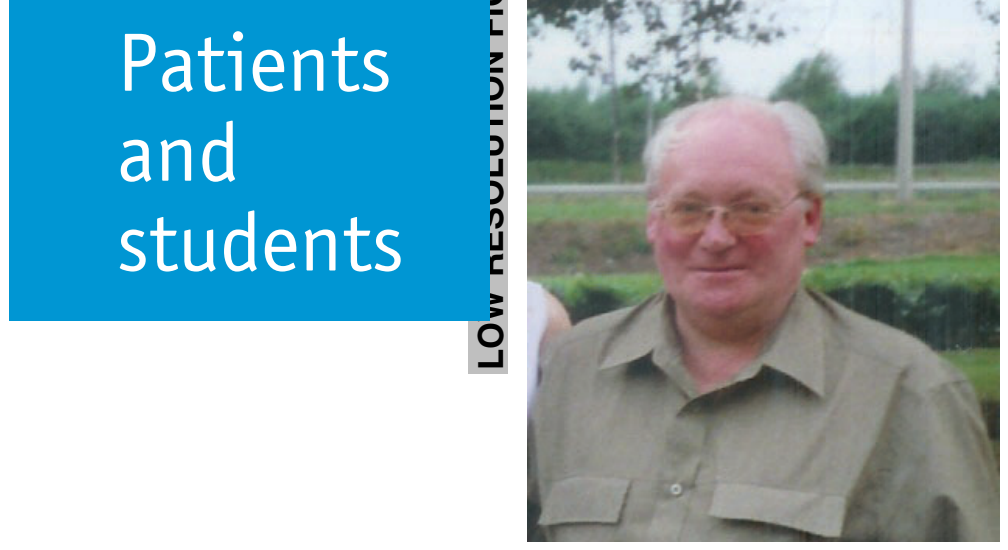

\title{
Should I ask my patient with cancer to teach
} students?

Janet Lefroy, Keele University School of Medicine, Keele, UK

\section{A} s clinical teachers, we want to provide access for our students to people living with and dying from cancer. A recent survey of British medical schools by the Centre for Cancer and Palliative Care Studies, of the Institute of Cancer Research, London found that some schools involved terminally ill patients directly in their teaching and most included hospice participation. ${ }^{1}$ The effect on people with cancer of telling others about their experience is of great concern to health care professionals who expose their patients in this way.

- Does teaching help or harm the patient?
- Does it add sufficient value to the medical students' learning programme to be worth this risk?

- Is damage limitation needed for the patient and the students?

These questions were brought into focus during a series of tutorials for fifth-year medical students about cancer from a patient's perspective. The patient was Ken, a physiotherapist. As Ken's GP I had gone through the worrying symptoms and initial referral stages with him, and had then met him on the rebound from a diagnosis of cancer of the stomach with liver metastases. He was already better informed than I was about prognosis and the latest ideas about disease-modifying therapies, both medical and self-help. Seeing his positive attitude and knowing that he had had a flair for teaching physiotherapy in the past, I asked him whether he would discuss his cancer with some medical students. Ken welcomed the invitation and enjoyed teaching the students. What I had not anticipated was how helpful the experience would be to him. After the first session he wrote to convey his thanks to the students for the opportunity that they gave him to discuss his situation openly, objectively and professionally.

This benefit to Ken of doing the teaching was the impetus for writing this paper. It may be of
Some schools involved terminally ill patients directly in their teaching 
What I had not anticipated was how helpful the experience would be to him help to other health care professionals thinking of asking their patients to teach in this way who might be wondering 'Is such teaching likely to help or harm my patient?'.

\section{WHAT WE DID}

During the summer of 2006, I asked Ken if he would consider teaching fifth-year students about cancer from the patient's viewpoint. Ken met with three successive groups of fifth-year medical students. The lesson plan was worked out jointly by Ken and me (Box 1). Ken started each seminar by introducing himself as a physiotherapist in private practice; he then asked the students to focus on cancer by giving them

\section{Box 1. Ken's lesson plan}

\section{Questionnaire}

An awareness exercise - each question to be answered individually and then discussed as a group facilitated by Ken

1. What do you understand by cancer?

2. Estimate the 5-year survival rate in the following:

Stage 1 Stage IV

Breast

Larynx

Mouth

Skin

Cervix

3. What can influence survival after cancer diagnosis?

4. What are the most common treatments for cancer?

5. Do you know of any other forms of treatment?

6. I have been diagnosed with primary adenocarcinoma of the stomach with multiple metastases in the liver and lymph glands (stage IV). What would you estimate my survival rate as?

- 5-year survival rate (answer $<2 \%$ )

- median survival rate (answer 8.7 months)

\section{Spot the cancer on my CT scans}

\section{Sharing of the experience of:}

- Being given the diagnosis

- Chemotherapy

- A Hickman line

- Self-help measures

- Follow-up investigation
Ken and I initially corresponded about his experience of teaching; later I asked him to reflect specifically on the effects of this teaching on him, with the aim of writing this paper together. At that time I asked the students to complete and return free text evaluations using the three questions in Box 2 which were developed in discussion with other experienced clinical teachers.

\section{WHAT WE FOUND}

\section{Student evaluation}

Of 14 students, 6 returned evaluations after a reminder email. Selected responses are shown in Box 2.

\section{Ken's evaluation}

Despite having anticipated the diagnosis, Ken wrote:

'I had begun to feel that maybe my useful life was over. I was struggling to maintain some points of reference for my continuing life. The request to discuss my situation with students gave me a positive and definite goal.

\section{'Students were obviously} keen to know how I coped with being told I had an 


\section{Box 2. Student responses to evaluation questions}

\section{Q: How relevant was this to your medical education?}

'Had a big impact on the way I perceive cancer patients ... what it feels like to have $a<0.2 \% 5$-year survival. In this way I learned never to look at a patient as a statistic ... provoked a lot of discussion later on about our expectations and assumptions.' Student C

'I saw how positive thinking has helped a particular patient ... I can help future patients ... going through chemotherapy even though I've never been through it myself.' Student D

'I now feel more comfortable discussing cancer with patients.' Student E

\section{Q: What did you learn that you consider might not have been done in a doctor-led tutorial?}

'When I walked into the tutorial the first thought that I had was: $\operatorname{Dr} \mathrm{L}$ and a tutor are here, so where is the cancer patient? When in fact the tutor was a cancer patient. It was very eye opening for all of us students.' Student $\mathrm{C}$

'Ken allowed us to ask questions that we may have otherwise been afraid to ask, e.g. how does one cope with the knowledge of a poor prognosis?' Student A

'I would have appreciated this tutorial earlier on in the course.' Student E

'I believe the major drawback to a patient-led tutorial is that different patients will have had a diverse range of experiences relating to how their condition has affected them. I felt that the gentleman who led our tutorial was very stoic and perhaps not a "typical" representation of those patients in a similar situation.' Student B

\section{Q: What were the negative aspects (for you) of being taught by this patient?}

None mentioned: five students

'Only the fear that Mr Stopani would perhaps not survive long enough to share his experience with more people.' Student C inoperable cancer. I explained how my background had, to some extent, prepared me for the worst news but that I still suffered a degree of denial. I had had a marked unwillingness to accept the prognosis and an early determination to prolong survival.
'I welcomed the discussion with up-to-date clinicians. Held in a professional manner, I found the students' incisive insights and questions, and the brutal honesty that sometimes only students can show in debate, both refreshing and challenging.'

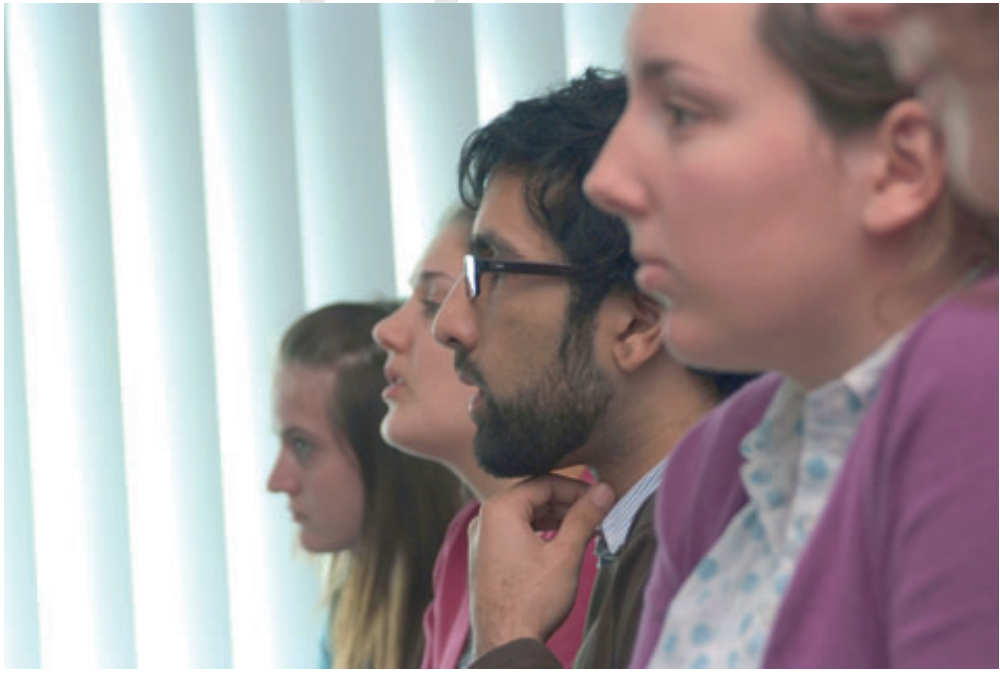

Ken's summary of what he gained from the teaching is shown in Box 3.

When asked about risk, Ken's response was that the risks were:

'Nothing compared to the risk of being told you have cancer!'

He added that if the students had not felt free to ask anything in their minds, then he would have felt that he had failed as a teacher. The challenges from them were the best bit. Having said that, he could accept that there might be a risk to other patients but felt that anyone agreeing to teach goes into it with his or her eyes open and should welcome a challenge.

\section{DISCUSSION}

I have described an evaluation by a patient teacher and final year medical students of their experience of respectively teaching and learning about terminal cancer. The experience was powerful for
The experience was powerful for students and unexpectedly positive for the patient 
There is

certainly a felt need for end-of-

life education among students

\section{Box 3. Ken: What I gained from teaching medical students about my cancer}

- I lost my apprehension and regained my confidence in addressing professional groups

- I was strengthened and invigorated by the challenge

- I was no longer pursuing a lone personal stoicism

- I recognised more readily the value of living in a wide group dynamic with the interest and support of others

- I enjoyed the confidence and freedom to discuss my situation

- I began to recognise where I lacked expertise and was able to identify those areas in which I was truly empowered to manage aspects of my own care

- I could firmly assert the core faith and beliefs that have sustained, and continue to sustain, me

- I was able to recognise areas of unthinking assumption and of limited analysis and understanding, and was thus able to identify areas for further personal study

Although many of the areas of discussion had been considered with my wife and friends, I found that the contributions of the students greatly aided and stimulated my intellectual enquiries and analyses, broadened my understanding of others' needs in my situation and helped to strengthen, through their rigorously honest discussion, my underlying core beliefs and those resulting decisions that I am uniquely empowered to make.

students and unexpectedly positive for the patient. Both patient and student respondents perceived that they had gained from their interaction.

Involvement of patients in teaching about terminal care is not novel. A literature review on undergraduate teaching of oncology $^{2}$ showed that involvement of cancer patients in teaching is popular with students, and encounters with these patients can have a lasting effect on the acquisition of communication skills. $^{3}$

\section{Is it legitimate to ask dying people to teach medical students?}

We are encouraged to invite patients to teach other patients or health care professionals because of the unique understanding of illness brought by the 'wounded story-teller'. The chronic neurological and rheumatological conditions have been considered particularly suitable for expert patients to teach. ${ }^{4}$ It may seem more risky to use those patients recently given a diagnosis of cancer as teachers, as these patients will usually be on a shorter and more changing journey than those living with chronic non-life-threatening conditions. They are still adjusting. Ken himself pointed out to the students that some patients want to be involved in discussing their case whereas others simply want to be the recipients of the best that can be done for them.

There is certainly a felt need for end-of-life education among students ${ }^{5}$ and students are well received by dying patients and their families. ${ }^{6}$ Our students found this encounter to be a

\section{Box 4. Hints for the clinical teacher}

Such experiences with dying patients are valuable, affecting students' skills and attitudes in end-of-life
- Suitable patients are those whose eyes light up when you ask them to talk to medical students

- Do some lesson planning with the patient

- Prepare the patient to feel challenged

- Prepare the students to meet a person with cancer (something like: 'be open but sensitive')

- Be ready to deal with student reactions - this can be a powerful experience

- Debrief your patient to see whether there is anything that he or she needs to discuss formative 2 hours (see Box 2), but the question remains as to how risky this is.

\section{Are there risks to the patient?}

Students do worry about causing harm to patients. ${ }^{7}$ This was discounted by Ken but he could accept that there might be a risk to other patients. Although Ken felt that those agreeing to undertake this role 'go in with their eyes open and they should welcome a challenge' it must be incumbent on the teacher to ensure that this is so.

\section{Are there risks to the student?}

It has been found that students do not become more afraid of death as a result of being exposed to dying patients. They do think more frequently about their own dying process and about interacting with a dying patient. ${ }^{8}$ In narrative analysis of preclinical students' feelings about a hypothetical dying patient, students overwhelmingly identified the need for coping strategies when confronting such a patient. ${ }^{9}$ Clinical teachers may be able to help students learn to cope by introducing them to patients, such as Ken, who are willing to talk about their cancer and about dying. There may be students, even so, who for personal reasons find such a discussion very difficult and need sensitive handling. 
Are these risks worth taking?

Such experiences with dying patients are valuable, affecting students' skills and attitudes in end-of-life care, as well as the emergence of their professional identities. ${ }^{10}$

\section{Summary}

Ken's account is encouraging to tutors wanting to involve patients with cancer as educators but we must still pause for thought. Teaching encounters will be beneficial to some patients. The task is identifying suitable patients at suitable times in their journeys. Ken has taught me that the teaching experience may well help patients to adjust to their situation, partly through the questioning of students, but this can feel challenging. We, as health care professionals in all areas who ask patients to be teachers, should consider how to prepare patients and students for the encounter, and how to debrief the patient afterwards (Box 4).
WAS IT WORTHWHILE?

On 22 July 2007, Ken came to the end of his journey rather sooner than he had planned, but still in control and a testament to the power of positive thinking. His widow, Lynne, confirms that it was good for Ken to have the focus of the student tutorials and writing down his experience for others to read. If this rather personal account encourages recruitment of patient teachers, then Ken's aim in writing will have been fulfilled.

\section{REFERENCES}

1. Field D, Wee B. Preparation for palliative care: teaching about death, dying and bereavement in UK medical schools 2000-2001. Med Educ 2002;36:561-567.

2. Gaffan J, Dacre J, Jones A. Educating undergraduate medical students about oncology: a literature review. J Clin Oncol 2006;24:1932-1939.

3. Klein S, et al. Eur J Cancer 2000;36:273-281.

4. Department of Health. The Expert Patient: A new approach to chronic disease management in the 21st century. London: The Stationery Office; 2001.

5. Wear D. Face-to-face with It: medical students' narratives about their end-of-life education. Acad Med 2002;77:271-277.

6. Ellman MS, Rosenbaum JR, Bia M. Development and implementation of an innovative ward-based program to help medical students acquire end-of-life care experience. Acad Med 2007;82:723-727.

7. Sarikaya 0, Civaner M, Kalaca S. The anxieties of medical students related to clinical training. Int J Clin Pract 2006:60:1414-1418.

8. Howells K, Gould M, Field D. Fear of death and dying in medical students: effects of clinical experience. Med Educ 1986;20:502-506.

9. Williams $\mathrm{CM}$, Wilson $\mathrm{CC}$, Olsen $\mathrm{CH}$. Dying, death, and medical education: student voices. J Palliat Med 2005;8:372-381.

10. Ratanawongsa N, Teherani A, Hauer KE. Third-year medical students' experiences with dying patients during the internal medicine clerkship: a qualitative study of the informal curriculum. Acad Med 2005;80:641-647. 


\section{Author Query Form}

\section{Journal: $\quad$ TCT}

\section{Article: $\quad 223$}

Dear Author,

During the copy-editing of your paper, the following queries arose. Please respond to these by marking up your proofs with the necessary changes/additions. Please write your answers on the query sheet if there is insufficient space on the page proofs. Please write clearly and follow the conventions shown on the attached corrections sheet. If returning the proof by fax do not write too close to the paper's edge. Please remember that illegible mark-ups may delay publication.

Many thanks for your assistance.

\begin{tabular}{|l|l|l|}
\hline $\begin{array}{l}\text { Query } \\
\text { reference }\end{array}$ & Query & Remarks \\
\hline 1 & $\begin{array}{l}\text { This is a low resoultion image. Please email a high quality, high resolution } \\
\text { image to Gallagher Yvonne [Yvonne.Gallagher@edn.blackwellpublishing. } \\
\text { com] along with all other proof corrections. }\end{array}$ & \\
\hline
\end{tabular}

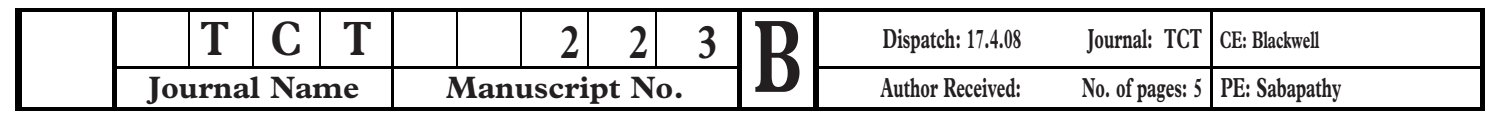




\section{Please correct and return this set}

Please use the proof correction marks shown below for all alterations and corrections. If you wish to return your proof by fax you should ensure that all amendments are written clearly in dark ink and are made well within the page margins.

\begin{tabular}{|c|c|c|}
\hline Instruction to printer & Textual mark & Marginal mark \\
\hline Leave unchanged & ... under matter to remain & ( ) \\
\hline $\begin{array}{l}\text { Insert in text the matter } \\
\text { indicated in the margin }\end{array}$ & $h$ & $\begin{array}{l}\text { New matter followed by } \\
h \text { or } h \otimes\end{array}$ \\
\hline Delete & $\begin{array}{l}\text { I through single character, rule or underline } \\
\text { or }\end{array}$ & $\sigma$ or $\sigma(x)$ \\
\hline $\begin{array}{l}\text { Substitute character or } \\
\text { substitute part of one or } \\
\text { more word(s) }\end{array}$ & I through letter or & $\begin{array}{l}\text { new character / or } \\
\text { new characters / }\end{array}$ \\
\hline Change to italics & — under matter to be changed & $\leftarrow$ \\
\hline Change to capitals & $\equiv$ under matter to be changed & $\equiv$ \\
\hline Change to small capitals & $=$ under matter to be changed & $=$ \\
\hline Change to bold type & $\sim$ under matter to be changed & $\sim$ \\
\hline Change to bold italic & $\bar{\sim}$ under matter to be changed & $\underline{s i n}$ \\
\hline Change to lower case & Encircle matter to be changed & $\Rightarrow$ \\
\hline Change italic to upright type & (As above) & \\
\hline Change bold to non-bold type & (As above) & \\
\hline Insert 'superior' character & $\begin{array}{l}/ \text { through character or } \\
K \text { where required }\end{array}$ & $\begin{array}{l}y^{\prime} \text { or } y \\
\text { under character } \\
\text { e.g. } y^{2} \text { or } y^{2}\end{array}$ \\
\hline Insert 'inferior' character & (As above) & $\begin{array}{l}\lambda \\
\text { over character } \\
\text { e.g. } \hat{\Sigma}\end{array}$ \\
\hline Insert full stop & (As above) & $\odot$ \\
\hline Insert comma & (As above) & , \\
\hline Insert single quotation marks & (As above) & $\begin{array}{l}\dot{y} \text { or } \dot{x} \text { and/or } \\
\dot{y} \text { or } \dot{y}\end{array}$ \\
\hline Insert double quotation marks & (As above) & $\begin{array}{l}\ddot{y} \text { or } \ddot{y} \text { and/or } \\
\ddot{y} \text { or } \ddot{y}\end{array}$ \\
\hline Insert hyphen & (As above) & 1 \\
\hline Start new paragraph & 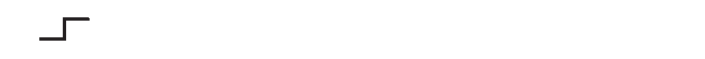 & 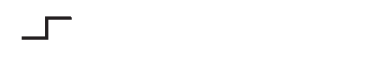 \\
\hline No new paragraph & $\infty$ & $\omega$ \\
\hline Transpose & $\sqcup$ & $\sqcup$ \\
\hline Close up & linking $\bigcirc$ characters & \\
\hline $\begin{array}{l}\text { Insert or substitute space } \\
\text { between characters or words }\end{array}$ & $\begin{array}{l}\text { I through character or } \\
\Lambda \text { where required }\end{array}$ & \\
\hline $\begin{array}{l}\text { Reduce space between } \\
\text { characters or words }\end{array}$ & $\begin{array}{l}\text { between characters or } \\
\text { words affected }\end{array}$ & $\uparrow$ \\
\hline
\end{tabular}

